\title{
Correction to: Forty years studies on polychlorinated biphenyls pollution, food safety, health risk, and human health in an e-waste recycling area from Taizhou city, China: a review
}

\author{
Muhammad Zaffar Hashmi ${ }^{1,2} \cdot$ Kezhen Chen $^{1} \cdot$ Foqia Khalid $^{3} \cdot$ Chunna Yu ${ }^{4} \cdot$ Xianjin Tang $^{1} \cdot$ Aili Li $^{1} \cdot$ Chaofeng Shen $^{1}$ \\ Published online: 23 December 2021 \\ ๑) Springer-Verlag GmbH Germany, part of Springer Nature 2021
}

\section{Correction to: Environmental Science and Pollution Research} https://doi.org/10.1007/s11356-021-17516-0

There are 2 corresponding Authors in this paper.

The Original article has been corrected.

Publisher's note Springer Nature remains neutral with regard to jurisdictional claims in published maps and institutional affiliations.

The original article can be found online at https://doi.org/10.1007/ s11356-021-17516-0

Muhammad Zaffar Hashmi

hashmi_qau@yahoo.com

$\triangle$ Chaofeng Shen

ysxzt@zju.edu.cn

1 Department of Environmental Engineering, College of Environmental and Resource Sciences, Zhejiang University, Hangzhou 310058, China

2 Department of Chemistry, COMSATS University Islamabad, Islamabad, Pakistan

3 College of Earth and Environmental Sciences, University of the Punjab, Lahore, Pakistan

4 College of Life and Environmental Sciences, Hangzhou Normal University, Hangzhou 310036, China 